\title{
Gluten free casein free diet as complementary and alternative medicine (CAM) treatment for children's with autism spectrum disorders (ASD)
}

\author{
Dipali Saxena $^{1 *}$, Shailja Jain ${ }^{2}$, Mukesh Changulani ${ }^{3}$, Richa Changulani ${ }^{4}$ and Shiv Kumar Jayant $^{5}$ \\ ${ }^{1}$ Centre for Food Technology, Jiwaji University, Gwalior, M.P., India \\ ${ }^{2}$ Department of Food \& Nutrition, Home Science, K.R.G.P.G. College, Gwalior, M.P., India \\ ${ }^{3}$ Antarman Psychiatry Centre, Gwalior, M.P., India \\ ${ }^{4}$ Assistant Professor (Former), Department of Preventive and Social Medicine, G.R. Medical College Gwalior, MP, India \\ ${ }^{5}$ Department of Biochemistry, AIIMS, Bhopal, India
}

\begin{abstract}
Autism is a developmental disorder that is marked by profound deficits in social, language, and cognitive abilities. GFCF diet is a complementary and alternative treatment for children's with autism which does not digest completely gluten and casein proteins and that the incompletely metabolized proteins leak into the digestive tract and travel through the bloodstream to the brain These peptides able to enter the bloodstream and act upon the central nervous system. The gluten free casein free (GFCF) diet is a common alternative intervention used for ASD management. The present study analyzes the effect of gluten free and casein free diet in children with autism in Gwalior city. This gluten free and casein free (GFCF) diet was administered twenty-five children who were in the experimental group and the other twenty were in the control group. Observation and evaluation were done before and after 3 months. A gluten-free and casein-free diet module was circulated to all the parent/ guardians. Parents were then told to exclude gluten and casein-based food products from the children s' diets for three months. Results show there was a significant difference between the two groups. Different improvements were seen in children which on diet than controls ones. This study suggests that a GFCF diet had an impact on the behavior of children with ASD positively, and highlights the importance of diet, including nutritional health benefits.
\end{abstract}

\section{Introduction}

Autistic Spectrum Disorders (ASD), is a neurological disorder characterized by socially aloof behavior and impairment of language and social interaction; it is a complex pervasive developmental disorder that involves the brain. The main characteristics in the definition of autism involve core deficits in three main areas of development, namely, social reciprocity, language \& communication, and repetitive behavior. Autism manifests in the first three years of life and persists into adulthood. Most cases emerge before the age of two and a half and few are diagnosed after the age of five [1]. Autism disorder varies from mild to severe, seldom it can be present alone or in addition to other conditions such as mental retardation, attention-deficit/ hyperactivity disorder (ADHD), anxiety disorders, depression or epilepsy; neurological problems such as brain cell differences and neurological chemical imbalances have been suggested as the cause of autism. Autism is a lifelong problem with a number of possible causes, including genetic problems or chromosomal defect, severe infections that affect the brain (celiac disease, etc.), exposure to toxins or illness during pregnancy (rubella, chemicals, etc.), vaccines or opiate activity. The incidence of ASD has been rising in the world in recent years. According to the Rehabilitation Council of India, between 1 in 166 children have an autistic spectrum disorder and greater incidence is found among boys (4:1).

Current alternative intervention services range from speech therapy, occupational therapy, physical therapy, to pharmacological therapy. Alternative therapies include various types of massage, nutritional interventions, auditory integration therapy, and more. A popular dietary intervention is a gluten-free, casein-free diet, which was developed based on a theory that the children have a "leaky gut", allowing peptides to act as brain opiates [2].

Despite positive anecdotal reports, no controlled studies have been done to test the effectiveness of the diet [3]. The diet can increase the risk of inadequate nutrient consumption [4]. For children with ASD, the nutrition assessment should include the possibility of medication (e.g. anticonvulsants, selective serotonin reuptake inhibitors, antipsychotics) and nutrient interactions, the use of any alternative therapies, herbals, and supplement use, and possible lead exposure [5].

A diet free of gluten and casein is very restrictive. All foods containing grains and dairy products are eliminated from the diet. As multiple forms of gluten and casein are used in many food products, the diet involves a lot of careful label reading. Many children with ASD have been on GFCF diets at one time or another, some for years at a time [6]. In a survey of the treatments they were currently using, $27 \%$

${ }^{\star}$ Correspondence to: Dipali Saxena, Centre for Food Technology, Jiwaji University, Gwalior, MP, India, E-mail: dipali.ju.ft@gmail.com

Key words: autism, diet, protein, gluten, casein, nutritional

Received: October 19, 2018; Accepted: November 05, 2018; Published: November 09, 2018 
of parents reported that their child with ASD was at that moment on an alternative diet and half had tried a special diet at one time or another [7].

Paul Shattock (2002) proposed an opioid excess theory, which states that peptides with opioid activity cross into the bloodstream from the lumen of the intestine, and then into the brain. These peptides were speculated to arise from incomplete digestion of certain foods, in particular gluten from wheat and certain other cereals and from casein from milk and dairy produce [8]. Seventy to eighty percent of people with autism have elevated levels of opioid peptides in their urine. These peptides are psychoactive and are originated from improperly digested proteins mainly casein and gluten [9]. These peptides are thought to leak out of the intestines into the bloodstream- referred to as the "leaky gut hypothesis" and are carried by the blood around the body and up to the brain. In the brain, they are thought to attach to opioid neuroreceptors and negatively impact neurotransmission, resulting in behavior problems and increased symptoms of ASD [8,10,11]. Figure 1 contains a schematic of the process suggested by the opioid excess theory.

Glutens are proteins found in the plant kingdom subclass of monocotyledons (monocots). These plants are members of the grass family of wheat, oats, rye, triticale and their derivatives. Casein is the phosphoprotein present in milk, which has a molecular structure that is extremely similar to that of gluten [12]. The exorphins i.e. casomorphins and gluteomorphins or ghadorphin, which are produced by the incomplete break down of casein and gluten are easily transferred across the lumen of the gut into the circulation where they exert opioidtype action on the brain [13].

So, a diet which excludes casein and gluten can help in the elimination of opioid peptides from the body of autistic children thereby helping to reduce the autistic symptoms. As there is an urge in the incidence of autism in India and there is dearth of information on the role of diets on autism, this study attempts to find out the efficacy of casein free and gluten free diet on selected autistic children with the following objectives as to study the background information, clinical history and nutritional status and dietary pattern of selected autistic children, to impart counseling to follow a casein free and gluten free diet and evaluate the impact of casein and gluten-free diet among selected autistic children.

\section{Aims and objectives}

The objective of this investigation was to determine the efficacy of gluten and casein free diet as a complementary and alternative treatment (CAM) treatment for children with autistic and aware the highlights of the importance of diet, including nutritional health benefits.

\section{Subjects and methods}

Three special schools, from Gwalior as, Gwalior society of Autism Samiti, Roshni and Antarman psychiatry center were selected by purposive sampling method. Background details such as age, sex, type of family and income status were elicited by interviewing the parents of the selected autistic children. The dietary module was circulated to all the parents in which foods to be avoided and which was a substitute for it (Table 1).

The autistic behavior was diagnosed by the Indian Scale for Assessment of Autism (ISAA) for measuring the severity of autism which was developed by the National Institute for Mentally Handicapped (NIMH) Hyderabad. This scale was based on CARS scale and has 40 items divided under six domains as social relationship and reciprocity, emotional responsiveness, speech, language and communication, behavior patterns; sensory aspects and a cognitive component. The items are rated from 1 to 5 , increasing score indicating increasing severity of the problem. A score of $<70$ indicates no autism, 70-106 (mild autism), 107-153 (moderate autism), and >153 (severe autism). It takes about 15 to 20 minutes for the administration of ISAA. The ISAA was devised with the aim of quantifying the severity of autistic symptoms so as to enable measurement of associated disability $[14,15]$ (Table 2).

\section{Methodology}

Anthropometric measurements like height and weight were recorded. Gluten free and casein free diet was imparted to the parents with the help of dietary module, which contains which foods to be avoided and which foods to be taken. Diet counseling regarding gluten free casein free diet was imparted to Group II. The diet was followed for a period of three months. The efficacy of the dietary exclusion of casein and gluten was evaluated using a food diary and $24 \mathrm{hr}$ recall method on a day to day basis. The parents were asked to record the day to day food intake of the subject in the food diary and the behavior improvements were observed simultaneously using the observation method. The ISAA SCALE was scale applied to both the groups as before and after the dietary intervention. The data was compiled and analyzed by using software SPSS 21 to determine the significant differences between the group I and group II.

\section{Observations}

\section{Anthropometric and clinical assessments}

The height and weight of the selected autistic children were less than ICMR standards of heights and weights for children at the start of the dietary intervention. Muscle wasting was noted in most autistic children. Most children belong to underweight.

\section{Diet history}

Among the twenty-five autistic children, twenty-three were boys and two were girls, in which ten children's were vegetarians, seven children's were not vegetarian, and eight children were over vegetarian. The mean nutrient intake of the selected autistic children shows that protein, fat, calcium intake was comparatively lower than the Recommended Dietary Allowance for children.
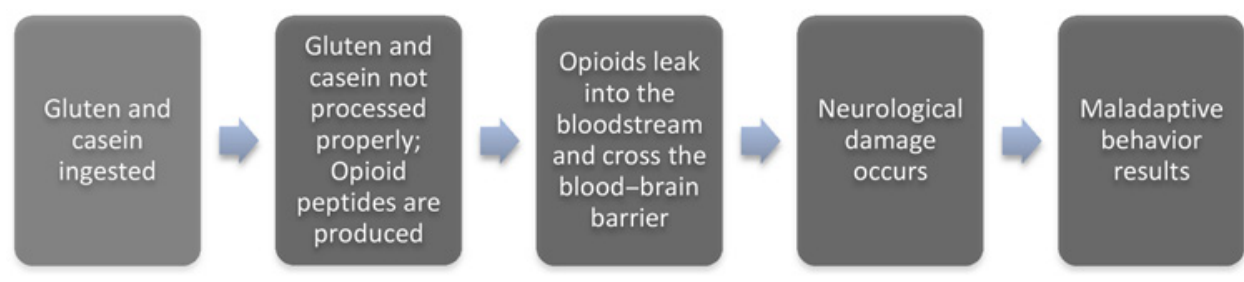

Figure 1. The chain of events suggested by the opioid-excess theory of autism, which proposes that eating gluten and casein affects the behavior of people with autism spectrum disorders 


\section{Impact of gluten free and casein free diet on the selected autistic children}

The impact of gluten free and casein free diet on autistic children on both the groups is given in Table 3. Five children dropped the diet. Results of Group II which followed dietary exclusion of gluten free casein free diet showed the improvement in ISSA scale.

Comparison of data of control and experimental before and after dietary intervention among the selected autistic children by SPSS 21 software is given in Table 4.

\section{Results and discussion}

From observations, it is clearly understood that there is a decrease in ISSA scale in group II (experimental) than the group I(control). As increased score indicating increasing severity of the problem and vice versa. This result agrees with that of Whiteley, et al. studies $[16,17]$. Out of twenty children of group II, five children dropped out the gluten and casein-free dietary intervention and only twenty children successfully followed the intervention with supplementation. This data also shows significant results in group II given in Table 4. Secondly, it was also seen that BMI of these children also improved towards normalcy.

Table 1. distribution of autistic children

\begin{tabular}{|c|c|c|c|c|}
\hline & \multicolumn{2}{|c|}{ Group I (Control) } & \multicolumn{2}{c|}{ Group II(Experimental) } \\
\hline $\begin{array}{c}\text { Category of } \\
\text { autism }\end{array}$ & Boys & Girls & Boys & Girls \\
\hline Mild & 11 & 00 & 14 & 01 \\
\hline Moderate & 07 & 02 & 09 & 01 \\
\hline Total & 18 & 02 & 23 & 02 \\
\hline Total Children & & 20 & & \\
\hline
\end{tabular}

Table 2. Classification as per ISAA score

\begin{tabular}{|c|c|c|c|c|}
\hline Classification & $\begin{array}{c}\text { No } \\
\text { Autism }\end{array}$ & $\begin{array}{c}\text { Mild } \\
\text { Autism }\end{array}$ & $\begin{array}{c}\text { Moderate } \\
\text { Autism }\end{array}$ & $\begin{array}{c}\text { Severe } \\
\text { Autism }\end{array}$ \\
\hline Total Score & $<70$ & $70-106$ & $107-153$ & $>153$ \\
\hline
\end{tabular}

Table 3. Impact of gluten and casein free diet

\begin{tabular}{|c|c|c|c|c|c|}
\hline \multicolumn{3}{|c|}{$\begin{array}{c}\text { Group I } \\
\text { (Control group) }\end{array}$} & \multicolumn{3}{c|}{$\begin{array}{c}\text { Group II } \\
\text { (Experimental group) }\end{array}$} \\
\hline S.NO. & Before & After & S.NO. & Before & After \\
\hline & 94.00 & 94.00 & & 118.00 & 105.00 \\
\hline & 122.00 & 122.00 & & 80.00 & 73.00 \\
\hline & 106.00 & 105.00 & & 104.00 & 98.00 \\
\hline & 85.00 & 82.00 & & 127.00 & 125.00 \\
\hline & 111.00 & 114.00 & & 106.00 & 107.00 \\
\hline & 98.00 & 98.00 & & 90.00 & 79.00 \\
\hline & 134.00 & 137.00 & & 119.00 & 111.00 \\
\hline & 129.00 & 131.00 & & 139.00 & 134.00 \\
\hline & 109.00 & 109.00 & & 101.00 & 95.00 \\
\hline & 97.00 & 96.00 & & 94.00 & 86.00 \\
\hline & 89.00 & 88.00 & & 113.00 & 102.00 \\
\hline & 102.00 & 111.00 & & 99.00 & 85.00 \\
\hline & 88.00 & 87.00 & & 126.00 & 118.00 \\
\hline & 91.00 & 94.00 & & 133.00 & 129.00 \\
\hline & 94.00 & 94.00 & & 112.00 & 102.00 \\
\hline & 123.00 & 122.00 & & 85.00 & 76.00 \\
\hline & 91.00 & 92.00 & & 103.00 & 90.00 \\
\hline & 139.00 & 134.00 & & 133.00 & 118.00 \\
\hline & 113.00 & 111.00 & & 109.00 & 104.00 \\
\hline & 122.00 & 124.00 & & 97.00 & 89.00 \\
\hline & & & & \\
\hline
\end{tabular}

Table 4. Comparison of data

\begin{tabular}{|c|c|c|}
\hline & $\begin{array}{c}\text { Group I } \\
\text { (Control) }\end{array}$ & $\begin{array}{c}\text { Group II } \\
\text { (Experimental) }\end{array}$ \\
\hline Mean difference & 0.4 & 8.10 \\
\hline Mean S.D. & 2.9498 & 4.08 \\
\hline Paired t-value & 0.623 & 8.857 \\
\hline Critical t value & 2.093 & 2.093 \\
\hline & No significance & There is significance \\
\hline
\end{tabular}

"Significant at five percent level

\section{Conclusion}

Gluten free and casein free is effective complementary and alternative medicine (CAM) for treatment of autism. Autism continues to increase in prevalence and remains an extreme challenge to medical management. This study suggests that a GFCF diet had an impact on the behavior of children with ASD positively, and highlights the importance of diet, including nutritional health benefits. Hence, a various healthy substitute is very important for this dietary intervention to reduce the drop out the dietary intervention. The expression of autism is so individualized that its management requires individualized care. Nutrients predictably have broader effects and better benefit to risk profiles than drugs. Nutrients predictably have broader effects and better benefit to risk profiles than drugs. It is advisable that parents attempt these interventions with the help of a nutritionist or other qualified practitioner, at least as a trial intervention.

\section{Acknowledgement}

I am grateful to my department, Department of Home Science (Foods and Nutrition) K.R.G P.G Autonomous College, Gwalior M.P. and Prof. G.B.K.S Prasad, Coordinator of Centre for Food Technology, Jiwaji University, Gwalior for all the facilities and opportunities that I have been provided. I also thankful to my guides Prof. Shailja Jain, Prof. Neeraj Jain, Dr. Mukesh Chunglani and Dr. Richa Changulani for their constant support and encouragement that they have provided throughout the work. I would also like to special thanks to Mr. Anshul Saxena (my husband), my friends, and my family for their motivation and encouragement.

\section{References}

1. Taylor B, Miller E, Lingam R, Andrews N, Simmons A, et al. (2002) Measles, mumps, and rubella vaccination and bowel problems or developmental regression in children with autism: population study. BMJ 324: 393-396. [Crossref]

2. Cook EH Jr, Arora RC, Anderson GM, Berry-Kravis EM, Yan SY, et al. (1993) Platelet serotonin studies in hyperserotonemic relatives of children with autistic disorder. Life Sci 52: 2005-2015. [Crossref]

3. Urakubo A, Jarskog LF, Lieberman JA, Gilmore JH (2004) Prenatal exposure to maternal infection alters cytokine expression in the placenta, amniotic fluid, and fetal brain. Schizophrenia Res 47: 27-36. [Crossref]

4. Busto R, Dietrich WD, Globus MY, Valdés I, Scheinberg P, et al. (1987) Small difference in intraischemic brain temperature critically determine the extent of the ischemic neuronal injury. J Cereb Blood Flow Metab 7: 729-738. [Crossref]

5. Croen LA, Grether JK, Hoogstrate J, Selvin S (2002) The changing prevalence of autism in California. J Autism Dev Disord 32: 207-215. [Crossref]

6. Pennesi Christine M, Cousino KL (2012) Effectiveness of the gluten- free, casein a free diet for children diagnosed with autism spectrum disorder: Based on parental report. Nutritional Neuroscience.

7. Smith T, Antolovich M (2000) Parental perceptions of supplemental interventions received by young children with autism in intensive behavior analytic treatment. Behavioral Interventions 15: 83-97.

8. Shattock P, Whiteley P (2002) Biochemical aspects in autism spectrum disorders: updating the opioid-excess theory and presenting new opportunities for biomedical intervention. Expert Opin Ther Targets 6: 175-183. [Crossref] 
9. Madsen KM, Hviid A, Vestergaard M, Schendel D, Wohlfahrt J, et al. (2002) A population-based study of measles, mumps, and rubella vaccination and autism. $N$ Engl J Med 347: 1477-1482. [Crossref]

10. Halsey NA, Hyman SL, Conference Writing Panel (2001) Measles-mumps-rubella vaccine and autistic spectrum disorder; report from the New Challenges in Childhood Immunizations Conference convened in Oak Brook, Illinois. Pediatr 107: E84. [Crossref]

11. Knivsberg AM, Reichelt KL, Høien T, Nødland M (2002) A randomised, controlled study of dietary intervention in autistic syndromes. Nutr Neurosci 5: 251-261. [Crossref]

12. Croonenberghs J, Bosmans E, Deboutte D, Kenis G, Maes M (2002) Activation of the inflammatory response system in autism. Neuropsychobiology 45: 1-6. [Crossref]
13. Whiteley P (2001) Autism unravelled conference--'the biology of autism-unravelled'. Expert Opin Pharmacother 2: 1191-1193. [Crossref]

14. http://www.nimhindia.org.autism-india.com/autism.../indian-scale-for-assessment-ofautism-isa

15. Indian scale for assessment of autism-test manual technical report (August 2008) https://www.researchgate.net/publication, doi: 10.13140/rg.2.1.3240.4004a

16. Gopalan C, Rama Sastri BV, Balasubramanian SC, National Institute of Nutrition (India) (2012) Nutritive value of Indian foods. National Institute of Nutrition, ICMR, Hyderabad.

17. ICMR and National Institute of Nutrition of Hyderabad (2010) Nutrients requirements and recommended dietary allowances for Indians.

Copyright: (2018 Saxena D. This is an open-access article distributed under the terms of the Creative Commons Attribution License, which permits unrestricted use, distribution, and reproduction in any medium, provided the original author and source are credited. 